\title{
An Evaluation of Sustainable Tourism Development in Hebei Province Based on the AHP
}

\author{
Donglin Wang \\ School of Management and Economics, Hebei University of Science \& Technology, Shijiazhuang, China \\ Liqin Lu \\ Shool of Accounting, Shijiazhuang University of Economics, Shijiazhuang, China
}

\begin{abstract}
In this paper, using the method of combining qualitative and quantitative, we conducted an indepth research to the sustainable tourism development theory, and then constructed an evaluation index system of sustainable tourism development in Hebei Province. Finally we used AHP to evaluate the tourism sustainable development status in Hebei Province, and found that in nearly 10 years, the tourism comprehensive evaluation score in Hebei Province is in an intermittent increase trend, and the trend is rather stable. Trying to tackle the existing problems in the sustainable development of tourism industry, we finally put forward some measures for promoting the sustainable development of tourism industry in Hebei Province. KEYWORD: AHP; Assessment Indicators; the Comprehensive Evaluation; Empirical Analysis
\end{abstract}

\section{INTRODUCTION}

Showing a rapid development trend in recent years, tourism in Hebei Province is a leading industry in the economy, and has a great potential. According to statistics from the National Tourism Bureau, the domestic tourism activities in Hebei Province in 2001 involved 5.3 million people, and the domestic tourism consumption totaled $¥ 23.44$ billion. In 2013, the domestic tourism activities involved 149 million people, and the domestic tourism consumption amounted to $¥ 89.08$ billion, the two figures increased several times comparing with that 10 years ago. Hebei is now a big tourism province, but it is not a strong tourism province. For the realization of sustainable development of the tourism, it is necessary to comprehensively reconsider the question through the establishment of an evaluation system.

\section{CONSTRUCTION OF INDICATORS OF EVALUATION SYSTEM}

\subsection{Establishment of the evaluation tree}

Hebei Province tourism sustainable development indicators tree includes 4 branches i.e.: the target layer, the system layer, the state layer and the factor layer. The highest level of the target layer is used to measure the overall level of the sustainable development of tourism in Hebei Province. The system layer includes four sub- systems, the tourism economy, the tourism resources, the environment support and the reception capacity. The state layer classifies the 4 sub-systems according to their characteristics. The factor layer shows the most representative factors of each subsystem.

\subsection{Evaluation index system}

According to the hierarchy of the design principles and indicators of the index system, the evaluation index system of sustainable development of tourism includes 4 sections: the tourism economy, the tourism resources, the environment support and the reception capacity, as well as 36 indicators, as shown in Table 1.

\section{ESTABLISHMENT OF SUSTAINABLE TOURISM DEVELOPMENT EVALUATION SYSTEM MODEL}

\subsection{Evaluation index weight determination}

The relative importance between the layers and the level of internal indicators are represented by the index weights given to each indicator. It is very important to decide how much is given to the index weight. Initially the index weight is given based on the subjective judgment of the study, but with further research, the method for determining index weight becomes more scientific[1]. This paper determines the method of index weight by analytic hierarchy method (AHP). 
Table 1. Evaluation index system of sustainable tourism development

\begin{tabular}{|c|c|c|c|}
\hline Target Layer & System Layer & State Layer & Factor Layer \\
\hline \multirow{36}{*}{$\begin{array}{l}\text { Evaluation index } \\
\text { system of } \\
\text { sustainable tourism } \\
\text { development in } \\
\text { Hebei Province } \\
\text { (A) }\end{array}$} & \multirow{10}{*}{$\begin{array}{l}\text { Tourism economy } \\
\text { (B1) }\end{array}$} & \multirow{5}{*}{$\begin{array}{l}\text { Economic } \\
\text { efficiency } \\
\text { (C1) }\end{array}$} & Domestic tourism income(D1) \\
\hline & & & Gross National Product (D2) \\
\hline & & & Added value of tertiary industry(D3) \\
\hline & & & International tourism income(D4) \\
\hline & & & Total Tourism Income(TTI) as percent of GDP(D5) \\
\hline & & \multirow{5}{*}{$\begin{array}{l}\text { Economic } \\
\text { structure } \\
\text { (C2) }\end{array}$} & Accommodation as percent of TTI (D6) \\
\hline & & & Catering as percent of TTI(D7) \\
\hline & & & Sightseeing as percent of TTI(D8) \\
\hline & & & Entertainment as percent of TTI(D9) \\
\hline & & & Tourism product as percent of TTI(D10) \\
\hline & \multirow{6}{*}{$\begin{array}{l}\text { Tourism resources } \\
\text { (B2) }\end{array}$} & \multirow{3}{*}{$\begin{array}{l}\text { Evaluation of } \\
\text { tourism resources } \\
\text { (C3) }\end{array}$} & Scarcity(D11) \\
\hline & & & Publicity (D12) \\
\hline & & & Location(D13) \\
\hline & & \multirow{3}{*}{$\begin{array}{l}\text { Protection of } \\
\text { tourism resources } \\
\text { (C4) }\end{array}$} & Forest cover $(\mathrm{D} 14)$ \\
\hline & & & Natural reserve, number(D15) \\
\hline & & & Natural reserve, area(D16) \\
\hline & \multirow{13}{*}{$\begin{array}{l}\text { Environments } \\
\text { support } \\
\text { (B3) }\end{array}$} & \multirow{9}{*}{$\begin{array}{l}\text { Social } \\
\text { environment } \\
\text { (C5) }\end{array}$} & Population (D17) \\
\hline & & & Employment(D18) \\
\hline & & & Urban unemployment rate (D19) \\
\hline & & & Net income per capita of rural family(D20) \\
\hline & & & Saving of residents at the end of year(D21) \\
\hline & & & R\&D as percent of GDP (D22) \\
\hline & & & Urban per capita living area (D23) \\
\hline & & & Urban per capita disposable income(D24) \\
\hline & & & The number of college students per ten thousand people (D25) \\
\hline & & \multirow{4}{*}{$\begin{array}{l}\text { Ecological } \\
\text { environment } \\
\text { (C6) }\end{array}$} & Environmental project investment (D26) \\
\hline & & & Industrial wastewater emission (D27) \\
\hline & & & Industrial solid waste emissions (D28) \\
\hline & & & Industrial sulfur dioxide emissions ( D29) \\
\hline & \multirow{7}{*}{$\begin{array}{l}\text { Reception capacity } \\
\text { (B4) }\end{array}$} & \multirow{4}{*}{$\begin{array}{l}\text { Tourism } \\
\text { Reception } \\
\text { (C7) }\end{array}$} & Domestic travel (D30) \\
\hline & & & International tourist arrivals (D31) \\
\hline & & & Number of hotel (D32) \\
\hline & & & Number of travel agencies (D33) \\
\hline & & \multirow{3}{*}{$\begin{array}{l}\text { Communication } \\
\text { (C8) }\end{array}$} & Civil aviation passenger transport (D34) \\
\hline & & & Railway passenger traffic volume (D35) \\
\hline & & & Highway passenger transport (D36) \\
\hline
\end{tabular}

\subsubsection{Establishment of a hierarchical model}

The establishment of a multi-level structure model requires us to classify the whole system into different layers according to the target and function[2]. The common characteristics compose new system-level factors. These factors make another group of higher levels of factors. Such layers progressively form the final single highest factor layer. The highest factor is the goal of the decision analysis. We need to quantify the relative importance between layers, and between the levels of the internal structure, and analyze the complex problems by breaking down into different levels of specific elements.

\subsubsection{Construct pair wise comparison judgment matrix}

After establishing the hierarchy model, we make pair wise comparisons to the factors of every layer, we can obtain a judgment matrix to reflect the relative importance between the levels. Then we quantify the relative factors according to the hierarchical structure model, and to compare their importance by the expert scoring method we can introduce a proportional scale to reflect the characteristics of the various factors to obtain the initial judgment matrix. Finally, we can arrive at the judgment matrix according to certain criteria layers of elements pair wise comparisons, as shown in Table 2.

Table 2. Judgment Matrix Scale and Their Meanings

\begin{tabular}{ccc}
\hline$f_{i j}$ scale & Meaning \\
\hline 1 & $f_{i}$ and $f_{j}$ equally important \\
3 & $f_{i}$ and $f_{j}$ A little important \\
5 & $f_{i}$ and $f_{j}$ obviously important \\
7 & $f_{i}$ and $f_{j}$ quite important \\
9 & $f_{i}$ and $f_{j}$ very important \\
$2,4,6,8$ & Between1-3, 3-5, 5-7 and 7-9 \\
$f_{j i}=1 / f_{i j}$ & Indicate the unimportance degree from $j$ to $i$ \\
\hline
\end{tabular}




\subsubsection{Level single-sort and consistency test}

Level single-sort: according to the judgment matrix to calculate the value of a certain level factors on a layer of a factor in the relative importance of the weights [3].

Level single sort consistency test:

1) Consistency index $C I$ : the greater the value of the consistency index means that the judgment matrix does not have a satisfactory consistency, $C I$ is smaller, the higher consistency.

$$
C I=\left(\lambda_{\max }-n\right) /(n-1)
$$

$n$ : The number of the order of the weight coefficient matrix;

$l_{\max }$ : The largest eigenvalue of the matrix.

2) Average random consistency index RI: repeated random judgment matrix eigenvalue calculation, the arithmetic average. The judgment matrix corresponding $R I$ values are shown in Table 3.

3) Random consistency ratio: If $C R$ is less than 0.1 , the judgment matrix has satisfactory consistency. If $C R$ is greater than 0.1 we must re-adjust the judgment matrix to make the value of the $C R$ in the range of 0.1 .

$$
C R=C I / R I
$$

\subsection{Indicators standardized method used}

An index system is composed by a number of indicators. The economic indicators represent different meaning and nature, we can not make direct evaluation for a total target. We need look for a way to make the indicators with comparable research questions. Before making decisions, we should standardize the process of evaluation. This method is called the standardized processing of the indicators. This is a process of transforming the indicators of the actual value to evaluation value. How to implement the transformation of evaluation index, from the mathematical point of view, is an index function between the actual value and evaluation value. From the point of view of geometrical, target standardization methods can be summed up in three categories: linear type, curve type and fold the linear normalization method. This paper uses the linear method for standardizing the indicators. Its formula is:

$$
X_{i}=x_{i} / \max x_{i}
$$

In the formula,

$\max x_{i}$ : The maximum of $x_{i}$.

$X_{i}$ : after dimensionless numbers. Reverse index of the treatment method is to take reciprocal value first, then to standardize the values.

For qualitative evaluation we use Delphi method to standardize processing: firstly, each of the indicators are divided into excellent $(A)$, good $(B)$, in $(C)$, and low $(D)$, poor $(E) 5$ level of each level coefficient 1.0, 0.8, $0.6,0.4,0.2$ scoring. Secondly, in accordance with the evaluation assessment of the indicators is given by the assessment panel experts (at least 8 or more) the score.
Finally, calculated by the formula (4).

$\phi=\sum \alpha / \beta$

In the formula,

$\phi:$ Qualitative index score values;

$\alpha$ : The evaluation experts selected level coefficient;

$\beta$ : The number of evaluation experts.

\subsection{The determination of evaluation methods and criteria}

\subsubsection{The determination of evaluation methods:}

Indices, which composite the index system for the sustainable development of tourism industry, can be reflected the overall situation of sustainable development comprehensively. In addition, the sustainable development evaluation results are analyzed comprehensively.

1) Four Integrative Evaluation Indexes

The paper confirms the relative significances of each monomial index at the same level and the comprehensive importance about the last level. And then the data obtained was merged with the linear weighting to get the only one. The corresponding evaluation values of four composite indexes in Hebei Province countermeasure were obtained. Its formula is as follows.

$$
F_{k}=\sum_{n=0}^{\infty} \lambda_{k i} u_{k i}
$$

$l_{k i}$ : Comprehensive index weight;

$u_{k i}$ : The single index weight;

$k(=1,2,3,4)$ is the score value of the tourism economy, the tourism resources, the tourism environmental support and the tourist reception capacity.

2) Comprehensive evaluation

The status of sustainable development of tourism can be reflected with the evaluation index system of indicators as a whole from multiple angles, and then conduct a comprehensive analysis of its results. First to determine the relative importance of the individual indicators in the level and on level important degree, and then put the resulting data to a linear weighted evaluation, we can derive four composite index corresponding evaluation values, the formula is as follows:

$$
Y=\sum_{i=1}^{m}\left[\sum_{j=1}^{n}\left(\sum_{k=1}^{i} I_{k} R_{k}\right) u_{j}\right] W_{i}
$$

$Y$ : Comprehensive score values;

$I_{k}$ : A single score value of the indicators;

$R_{k}$ : The weight of the single parameter under the layer;

$u_{j}$ : The four factors level index weight.

$W_{i}$ : The four factors weight.

\subsubsection{The classification standard}

Hebei Province tourism sustainable development is divided into five stages, as shown in Table 4. 
Comprehensive evaluation value $0.6-0$ the unsustainable stage, $0-0.5$ for the preparation phase, $0.5-0.8$ for the preliminary stage, $0.8-1$ for the basic stage, more then value 1 for the sustainable development stage, different stages can be developed depending on the situation operational milestones. This facilitates the goal of sustainable tourism development stage breakthroughs in key areas.

Table 3. Average random consistency $R I$ values

\begin{tabular}{|c|c|c|c|c|c|c|c|c|c|c|c|}
\hline$n$ & 1 & 2 & 3 & 4 & 5 & 6 & 7 & 8 & 9 & 10 & 11 \\
\hline$R I$ & 0.00 & 0.00 & 0.58 & 0.90 & 1.12 & 1.24 & 1.32 & 1.41 & 1.45 & 1.49 & 1.51 \\
\hline
\end{tabular}

Table 4. Tourism sustainable development evaluation standards

\begin{tabular}{|c|c|c|c|c|c|}
\hline $\begin{array}{c}\text { Comprehensive } \\
\text { Evaluation value(Y \%) }\end{array}$ & $-0.6-0$ & $0-0.5$ & $0.5-0.8$ & $0.8-1$ & $>1$ \\
\hline Valuation standards & $\begin{array}{c}\text { Unsustainable } \\
\text { Development stage }\end{array}$ & Preparation stage & Preliminary stage & Basic stage & $\begin{array}{c}\text { Sustainable } \\
\text { Development stage }\end{array}$ \\
\hline
\end{tabular}

Table 5. The tourism sustainable development in Hebei Province comprehensive evaluation results

\begin{tabular}{|c|c|c|c|c|c|c|c|c|c|c|}
\hline Year & 2004 & 2005 & 2006 & 2007 & 2008 & 2009 & 2010 & 2011 & 2012 & 2013 \\
\hline Tourism economy system & 0.0304 & 0.0524 & 0.0217 & 0.0357 & 0.0395 & 0.0436 & 0.0480 & 0.0494 & 0.0590 & 0.0647 \\
\hline Tourism resource system & 0.1497 & 0.1738 & 0.1857 & 0.1993 & 0.2302 & 0.2375 & 0.2338 & 0.2366 & 0.2382 & 0.2534 \\
\hline Environment support system & 0.2203 & 0.2657 & 0.2767 & 0.3727 & 0.3966 & 0.4111 & 0.4187 & 0.3732 & 0.4079 & 0.4385 \\
\hline Reception ability system & 0.0487 & 0.0534 & 0.0449 & 0.0605 & 0.0668 & 0.0763 & 0.0826 & 0.0845 & 0.0939 & 0.1088 \\
\hline Score & 0.4490 & 0.5452 & 0.5290 & 0.6681 & 0.7331 & 0.7685 & 0.7831 & 0.7437 & 0.7990 & 0.8654 \\
\hline
\end{tabular}

Table 6. Tourism sustainable development status in Hebei Province

\begin{tabular}{|c|c|c|c|c|c|c|c|c|c|}
\hline Year & 2005 & 2006 & 2007 & 2008 & 2009 & 2010 & 2011 & 2012 & 2013 \\
\hline Score & 0.4490 & 0.5452 & 0.6681 & 0.7331 & 0.7685 & 0.7831 & 0.7437 & 0.7990 & 0.8654 \\
\hline Status & Preparation & Preliminary & Preliminary & Preliminary & Preliminary & Preliminary & Preliminary & Preliminary & Basic \\
\hline
\end{tabular}

\section{EMPIRICAL ANALYSIS OF SUSTAINABLE TOURISM DEVELOPMENT IN HEBEI PROVINCE}

\subsection{Comprehensive analysis results}

We first determine the relative importance of each factor in the level and on level important degree, and then linear weighting the data. The resulting data from 2004 to 2013 is calculated by the formula (5). We obtained the corresponding value of the four composite indexes in Hebei Province tourism sustainable development, and then by the weight of each subsystem in the total level multiplied by the corresponding four sub-systems of the comprehensive score. Finally by the formula (6), we arrived at a comprehensive evaluation of the results from 2004 to 2013 of sustainable tourism development in Hebei Province, as shown in Table 5.

\subsection{Comprehensive evaluation score of grading}

Hebei Province tourism sustainable development is divided into five stages, the unsustainable stage, the preparation stage, the preliminary stage, the basic stage and the sustainable development stage. In different stages of development, we can make different operational policies and targets, based on different circumstances. This facilitates breakthroughs in key areas and to reach the goal of sustainable tourism development. According to Table 3.3, we have Hebei
Province sustainable tourism development status, as shown in Table 6.

\section{CONCLUSIONS}

Generally speaking, comprehensive evaluation score of the tourism industry in Hebei Province from 2004 to 2013 is rather smooth, fluctuation is not big. But due to the impact of the financial crisis in 2008, tourism there severely affected, in the following years, the comprehensive evaluation score in Hebei Presents a stable increase trend. Various factors in recent years, including the industrial structure changes and frequent promotion policy adjustments, make single evaluation index score improved.

\section{REFERENCES}

[1] Lihua Shen, Introduction to Tourism Economics, China Economic Publishing House, Beijing, 2001.

[2] Yongxue Shan, "A Study on index system of sustainable tourism development in Anhui Province", Modern Business Trade Industry, Vol. 11, No. 64, pp. 110-113, Jun. 2010.

[3] Ping Yin, and Zhongyu Ma, "Assessment Study on Sustainable Development for Beijing's Tourism", Journal of Beijing Jiaotong University (Social Sciences Edition), Vol. 2, No. 14, pp. 68-72, Feb. 2009. 